\title{
Platelet Distribution Width from Two Automated Hematology Analysers: A Correlation Analysis
}

Eunyup Lee, Han-Sung Kim, Hee Jung Kang, Miyoung Kim, and Young Kyung Lee Department of Laboratory Medicine, Hallym University Sacred Heart Hospital, Hallym University College of Medicine, Anyang, Korea

Corresponding author: Miyoung Kim Department of Laboratory Medicine, Hallym University Sacred Heart Hospital, Hallym University College of Medicine, 22 Gwanpyeong-ro 170beongil, Dongan-gu, Anyang 14068, Korea

Tel: +82-31-380-1795

Fax: +82-31-380-1798

E-mail: rabbit79@hallym.or.kr
Platelet distribution width (PDW) is an index for platelet size variation. In this study, we analysed the correlation between PDW values obtained using two different hematology analysers that employ different measurement methods. Complete blood cell parameters including PDW for 153 healthy individuals were measured using both, ADVIA 2120i (Simens AG, Germany) and XN-3000 (Sysmex, Japan). The PDW values measured using the two hematology analysers showed a moderate correlation $(r=0.661, P<0.001)$, while the hemoglobin, mean corpuscular volume, red blood cell distribution width values and white blood cell and platelet counts showed strong correlations $(r>0.900, P<0.001)$. PDW obtained using XN-3000 showed a strong correlation with mean platelet volume, whereas PDW obtained using ADVIA 2120i did not. The reference values in this group were $40.0 \%-$ 64.2\% in ADVIA 2120i and 9.0-16.0 fL in XN-3000. In conclusion, PDW values obtained using ADVIA 2120i and XN-3000 are not interchangeable. In laboratories equipped with more than one hematology analyser, a particular analyser should be used consistently for monitoring a particular patient.

(J Lab Med Qual Assur 2017;39:42-46)

Key Words: Platelet distribution width, ADVIA 2120i, XN-3000 혈소판분포폭(platelet distribution width, PDW)은 자동혈 구분석기를 이용한 혈액검사에서 보고되는 혈소판지표 중 하 나로, 혈소판의 크기와 모양의 분포를 나타내는 지표이다. 혈 소판이 활성화되면 구 모양과 위족이 형성되며 그 형태가 변 하고 수가 다양한 정도로 증가하여 $\mathrm{PDW}$ 에 영향을 끼친다 〔1]. 최근 다양한 질환에서 $\mathrm{PDW}$ 의 임상적 의의가 제시되었으 며, PDW는 활동성 혈전색전질환에서 염증 및 혈전생성상태 를 반영하여 평균혈소판용적(mean platelet volume, MPV) 과 함께 증가함이 제시되었다[2]. 또한 혈관성 치매와 알츠 하이머병을 구별하는 지표로도 사용될 수 있음이 제시되었다
[3,4]. 그러나 이와 같은 관심에도 불구하고 $\mathrm{PDW}$ 는 자동혈 구분석기에 따라 측정법 및 보고단위가 다르며, 그 값의 호환 성에 관한 연구는 이루어진 바 없어 실제 임상 적용의 어려움 으로 작용한다. 본 연구에서는 널리 이용되는 자동혈구분석기 인 ADVIA 2120i (Simens AG, Eschborn, Germany)와 XN3000 (Sysmex, Kobe, Japan)에서 얻어진 PDW 값의 상관성 을 분석하고, 심혈관계 질환, 뇌혈관계 질환에서의 $\mathrm{PDW}$ 의 변 화를 비교하였다.

연구기간은 2015년 4월부터 11월까지로, 해당 기간 내에 건강검진을 목적으로 한림대학교성심병원을 내원한 성인 중 


\title{
Journal of LABORATORY MEDICINE and QUALITY ASSURANCE
}

\author{
Eunyup Lee et al • PDW from Two Hematology Analysers
}

일반혈액검사의 전 항목이 참고범위 내에 있으며, 특정 질환 이 없는 것으로 밝혀진 153명을 대상으로 하였다. $\mathrm{K}_{2}-\mathrm{EDTA}$ 항응고제를 사용한 신선 전혈 $3 \mathrm{~mL}$ 를 $\mathrm{ADVIA} 2120 \mathrm{i}$ 와 XN3000 로 1 시간 이내의 시간차를 두고 측정하였다. 두 기기 간 의 PDW를 비롯한 일반혈액검사결과의 상관성을 확인하기 위해 Pearson 상관분석을 이용하였다. 또한 PDW와 혈소 판 수(platelet count), $\mathrm{MPV}$, 연령과의 상관관계를 확인하 기 위하여 Pearson 상관분석을 적용하였다. 기기에 따른 정 상인의 PDW 참고치 설정을 위하여 Shapiro-Wilk test와 Kolmogorov-Smirnov test를 이용한 정규성 검정 후 2.5 백 분위수, 97.5 백분위수를 각각 참고치 하한, 참고치 상한 값으 로 정하였다. 통계분석은 IBM SPSS ver. 23.0 (IBM Corp., Armonk, NY, USA)를 이용하여 수행하였으며, $P$-value가 0.05 미만을 통계적으로 유의하다고 해석하였다. 본 연구는 한 림대학교성심병원 기관윤리심의위원회의 심의를 통과하였다 (IRB No. 2016-I030).

대상자 153 명의 성비는 남:여 $=119: 34$ 이었으며, 평균 연

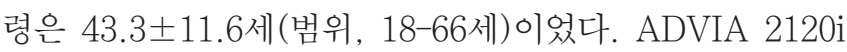
와 XN-3000 간에 혈색소(hemoglobin), 평균적혈구용적 (mean corpuscular volume), 적혈구분포폭(red blood cell distribution width), 백혈구 수(white blood cell count), 혈소 판 수, $\mathrm{MPV}$ 지표는 강한 양의 상관관계를 보였고 평균적혈구 혈색소농도(mean corpuscular hemoglobin concentration) 는 중등도의 양의 상관관계를 보였다(Table 1). 그러나 PDW 의 두 장비 간 상관관계는 중등도의 양의 상관관계를 보였다 $(r=0.661, P<0.001)$ (Fig. 1). ADVIA 2120i에서 PDW는 혈 소판 수와 약한 음의 상관관계를 보였으며, MPV와는 중등도 의 양의 상관관계를 보였고, 나이와의 상관관계는 통계적인 의의가 없었다. XN-3000에서 PDW는 혈소판 수와는 중등도
의 음의 상관관계를 보였으며, MPV와는 강한 상관관계를 보 였고 $(r=0.957, P<0.001)$, 나이와의 상관관계는 통계적인 의 의가 없었다(Fig. 2). PDW의 참고치는 ADVIA $2120 \mathrm{i}$ 와 XN3000에서 각각 40.0\%-64.2\%, 9.0-16.0 fL이었다.

국내에서 가장 널리 사용되는 자동혈구분석기인 $\mathrm{ADVIA}$ $2120 \mathrm{i}$ 와 XN-3000은 각각 다른 $\mathrm{PDW}$ 측정방법을 이용하고 있 다. ADVIA $2120 \mathrm{i}$ 의 PDW는 MPV를 표준편차로 나눈 계산 값을 백분율로 표현한다[5]. 반면, $\mathrm{XN}-3000$ 장비에서는 $\mathrm{x}$ 축 을 혈소판 크기, $\mathrm{y}$ 축을 각 크기에 해당하는 혈소판의 개수로 하여 그린 히스토그램에서 가장 많은 혈소판 수를 $100 \%$ 로 가 정하였을 때, 하위, 상위 $20 \%$ 혈소판 수 지점의 혈소판 크기 의 차를 PDW로 한다[6]. 이와 같이 자동혈구분석기에 따라

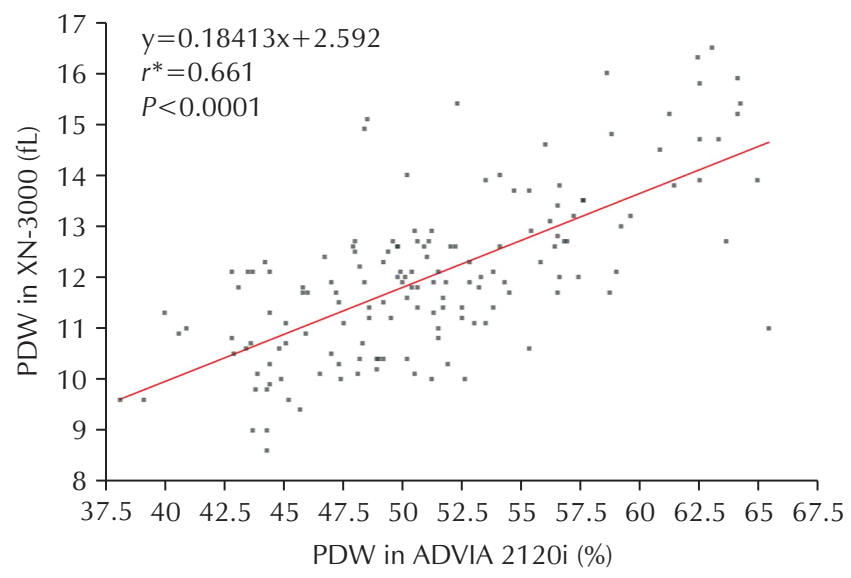

Fig. 1. Correlation between PDW measured using ADVIA 2120i and XN-3000 for 153 healthy individuals. Abbreviation: PDW, Platelet distribution width. The following test was used: ADVIA 2120i (Simens AG, Eschborn, Germany) and XN3000 (Sysmex, Kobe, Japan). ${ }^{*}$ Pearson’s correlation coefficient.

Table 1. Correlations between complete blood cell count parameters measured using ADVIA 2120i and XN-3000 analysers

\begin{tabular}{|c|c|c|c|c|c|}
\hline & \multicolumn{2}{|c|}{ Analyser } & \multirow{2}{*}{ Equation } & \multirow{2}{*}{$\begin{array}{c}\text { Pearson's } \\
\text { coefficient }(r)\end{array}$} & \multirow{2}{*}{$P$-value } \\
\hline & ADVIA 2120i & $\mathrm{XN}-3000$ & & & \\
\hline $\mathrm{Hb}(\mathrm{g} / \mathrm{L})$ & $144 \pm 13$ & $146 \pm 14$ & $y=1.0468 x-0.5707$ & 0.988 & $<0.0001$ \\
\hline Mean corpuscular volume (fL) & $89.7 \pm 4.1$ & $92.6 \pm 4.2$ & $y=0.9826 x+4.374$ & 0.952 & $<0.0001$ \\
\hline Mean corpuscular $\mathrm{Hb}$ concentration (fraction) & $0.346 \pm 0.011$ & $0.328 \pm 0.009$ & $y=0.4782 x+16.59$ & 0.633 & $<0.0001$ \\
\hline Red blood cell distribution width-CV (fraction) & $0.126 \pm 0.006$ & $0.121 \pm 0.008$ & $y=1.218 x-2.782$ & 0.930 & $<0.0001$ \\
\hline White blood cell count $\left(\times 10^{9} / \mathrm{L}\right)$ & $6.2 \pm 1.76$ & $7.1 \pm 1.7$ & $y=0.9857 x-43.95$ & 0.990 & $<0.0001$ \\
\hline Platelet count $\left(\times 10^{9} / \mathrm{L}\right)$ & $246.0 \pm 49.2$ & $217.0 \pm 52.8$ & $y=1.056 x+0.7873$ & 0.983 & $<0.0001$ \\
\hline Mean platelet volume (fL) & $10.7 \pm 0.8$ & $12.1 \pm 0.8$ & $y=0.7622 x+3.716$ & 0.799 & $<0.0001$ \\
\hline
\end{tabular}

Values are presented as mean \pm SD. The following test was used: ADVIA 2120i (Simens AG, Eschborn, Germany) and XN-3000 (Sysmex, Kobe, Japan).

Abbreviation: Hb, haemoglobin. 


\section{Journal of LABORATORY MEDICINE and QUALITY ASSURANCE}

\section{Eunyup Lee et al • PDW from Two Hematology Analysers}
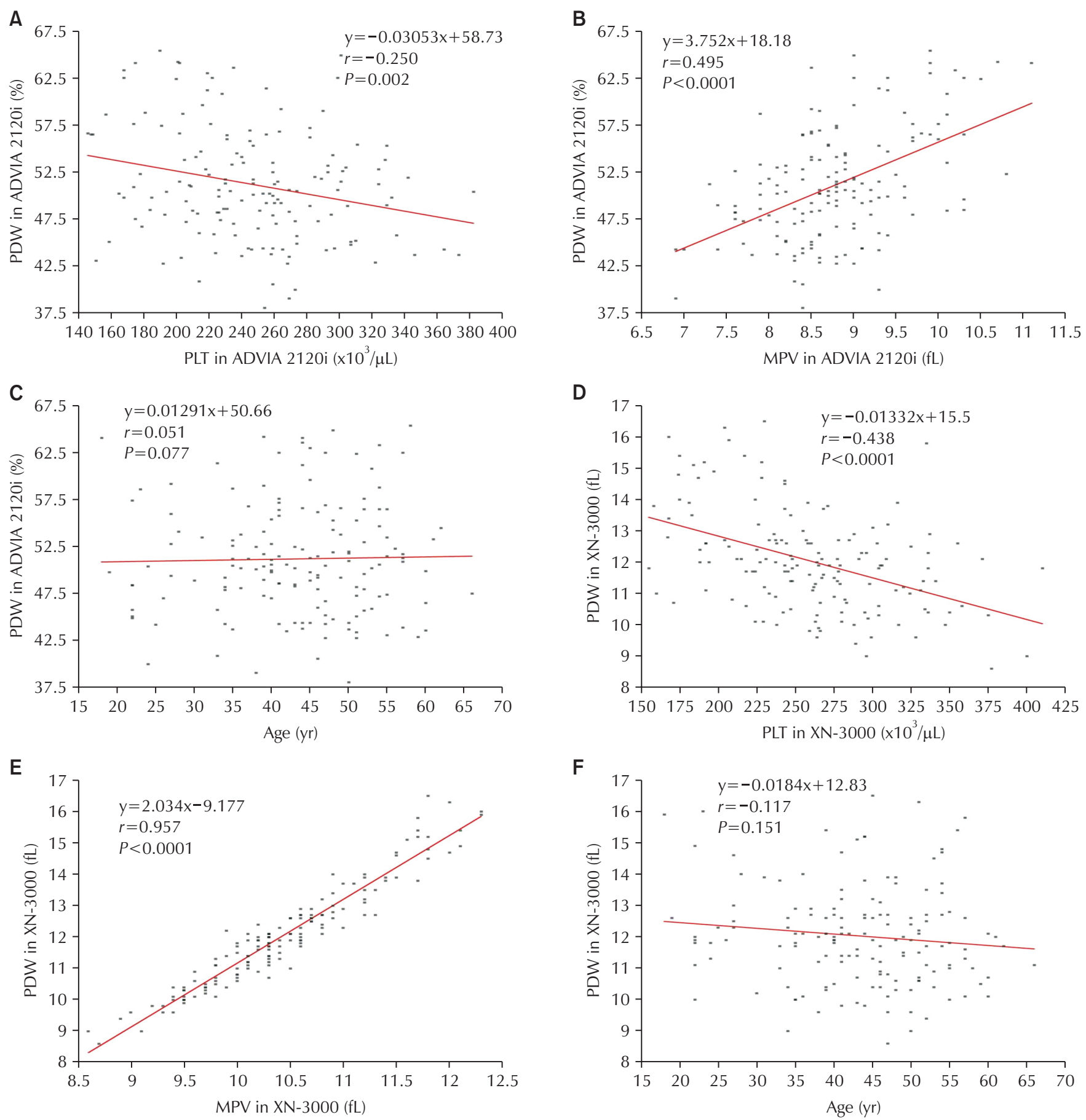

Fig. 2. Correlation between PDW and PLT, MPV measured using ADVIA 2120i and XN-3000 for 153 healthy individuals. (A) Correlation between PDW and PLT measured using ADVIA 2120i; (B) Correlation between PDW and MPV measured using ADVIA 2120i; (C) Correlation between PDW measured using ADVIA 2120i and age; (D) Correlation between PDW and PLT measured using XN-3000; (E) Correlation between PDW and MPV measured using XN-3000; (F) Correlation between PDW measured using XN-3000 and age. Abbreviations: PLT, platelet count; MPV, mean platelet volume; PDW, platelet distribution width. The following test was used: ADVIA 2120i (Simens AG, Eschborn, Germany) and XN-3000 (Sysmex, Kobe, Japan). 


\section{Journal of LABORATORY MEDICINE and QUALITY ASSURANCE}

Eunyup Lee et al PDW from Two Hematology Analysers

$\mathrm{PDW}$ 를 측정하는 원리와 보고단위에 차이가 있음에도 불구하 고, 서로 다른 장비에서 측정된 $\mathrm{PDW}$ 값의 호환성에 대해서는 연구된 바가 없으며[7], 이는 PDW의 임상적 의의에 관한 연 구에 선행되어야 한다.

본 연구결과에 따라 ADVIA 2120i와 XN-3000에서 제공하 는 대표적인 일반혈액검사지표 중 PDW를 제외한 다른 항목 에서는 강한 상관관계를 나타냄에 반해 PDW 값의 연관성은 있으나 호환은 불가능할 것으로 판단된다. 따라서 PDW 측정 원리가 서로 다른 둘 이상의 자동혈구분석기를 동시에 사용하 는 검사실에서는 직접 호환성 비교를 실시해야 한다. 또한 호 환이 불가능하다고 판단되는 경우 특정 환자의 PDW 모니터 링을 위해서는 동일 기기를 사용할 것이 추천된다.

\section{감사의 글}

이 논문은 대한임상검사정도관리협회의 2015년 학술연구비 지원을 받아 시행한 자유과제(실험연구, 과제번호 2015-7) 결 과를 바탕으로 작성되었다.

\section{REFERENCES}

1. Vagdatli E, Gounari E, Lazaridou E, Katsibourlia E,
Tsikopoulou F, Labrianou I. Platelet distribution width: a simple, practical and specific marker of activation of coagulation. Hippokratia 2010;14:28-32.

2. Gasparyan AY, Ayvazyan L, Mikhailidis DP, Kitas GD. Mean platelet volume: a link between thrombosis and inflammation? Curr Pharm Des 2011;17:47-58.

3. Wang RT, Jin D, Li Y, Liang QC. Decreased mean platelet volume and platelet distribution width are associated with mild cognitive impairment and Alzheimer's disease. J Psychiatr Res 2013;47:644-9.

4. Liang QC, Jin D, Li Y, Wang RT. Mean platelet volume and platelet distribution width in vascular dementia and Alzheimer's disease. Platelets 2014;25:433-8.

5. Kim MJ, Park PW, Seo YH, Kim KH, Seo JY, Jeong JH, et al. Reference intervals for platelet parameters in Korean adults using ADVIA 2120. Ann Lab Med 2013;33:364-6.

6. Sysmex Europe GmbH. Platelet distribution curves: interpretation, potentials and limitations. http://www. sysmex-europe.com/ (Accessed June 1, 2016).

7. Osselaer JC, Jamart J, Scheiff JM. Platelet distribution width for differential diagnosis of thrombocytosis. Clin Chem 1997;43(6 Pt 1):1072-6. 


\section{두 자동혈구분석기 간의 혈소판분포폭의 상관성 분석} 이은엽 • 김한성 • 강희정 • 김미영 • 이영경

한림대학교 의과대학 한림대학교성심병원 진단검사의학과

혈소판분포폭(platelet distribution width, PDW)은 혈소판의 크기의 분포를 나타내는 지표이다. 본 연구에서는 $\mathrm{XN}-3000$ 과 $\mathrm{ADVIA} 2120 i$ 장비에서 측정한 PDW의 상관관계에 대해 분석하였다. 건 강 성인 153명을 대상으로 하여, ADVIA 2120i (Simens AG, Germany)와 XN-3000 (Sysmex, Japan)로 PDW를 비롯한 complete blood cell count 검사를 시행하였다. 두 기기에서 측정된 혈 색소(hemoglobin), 평균적혈구용적(mean corpuscular volume), 적혈구분포폭(red blood cell distribution width), 백혈구 수(white blood cell count), 혈소판 수(platelet count)는 모두 강한 상 관관계를 보임에 반하여 $(r>0.900, P<0.001), \mathrm{PDW}$ 는 중등도의 상관관계를 나타내었다 $(r=0.661$, $P<0.001) . X N-3000$ 의 PDW는 평균혈소판용적(mean platelet volume)와 강한 상관관계를 나타 내었으나, ADVIA 2120i의 PDW는 그렇지 않았다. 결론적으로, 두 기기 간의 PDW 값은 호환이 불 가능함을 확인하였으며, 두 종류 이상의 자동혈구분석기를 보유한 기관에서는 특정 환자의 모니터링 을 위해서는 특정 기기만을 이용할 것이 추천된다.

(J Lab Med Qual Assur 2017;39:42-46) 